\title{
Penguatan Pendidikan Etika dan Karakter Peduli Lingkungan Sosial Budaya di SMP Muhammadiyah 10 Matesih, Karanganyar
}

\author{
Koesoemo Ratih ${ }^{1}$, Ratnasari Dyah Utami ${ }^{2}$, Djalal Fuadi ${ }^{3}$, Sri Mulyasih ${ }^{4}$, Dinar Febriani ${ }^{5}$, Sampdoria \\ Fajar Asmara ${ }^{6}$, Diana Riza Aprilianti ${ }^{7}$, Arum Wahyu Rianti ${ }^{8}$, Dewi Santiana ${ }^{9}$, Heni Rahmawati ${ }^{10}$, \\ Livya Mora Adlina $^{11}$, Bastian Rosyidi ${ }^{12}$, Muhammad Taufik Hidayat ${ }^{13}$ \\ 1,2,3,4,5,6,7,8,9,10,11,12,13 Fakultas Keguruan dan Ilmu Pendidikan, Universitas Muhamamdiyah Surakarta, \\ Indonesia
}

\section{INFORMASI ARTIKEL}

\begin{tabular}{l} 
Histori Artikel: \\
Submit: 20 Mei 2020 \\
Revisi: 3 Juli 2020 \\
Diterima: 5 Juli 2020 \\
Publikasi: 12 Juli 2020 \\
Periode Terbit: Juli 2020 \\
\hline Kata Kunci: \\
etika, \\
karakter, \\
komunikasi global, \\
peduli lingkungan
\end{tabular}

Correspondent Author:

Koesomo Ratih

Fakultas Keguruan dan Ilmu Pendidikan

Universitas Muhammadiyah Surakarta,

Indonesia

Email: koesoemo.ratih@ums.ac.id

\begin{abstract}
ABSTRAK
Tujuan utama kegiatan pengabdian masyarakat ini adalah untuk menumbuhkan dan memberikan penguatan kepedulian guru dan siswa di SMP Muhammadiyah 10 Matesih Karanganyar terhadap lingkungan sosial-budaya sekolah dalam pendidikan etika dan karakter di era komunikasi global sekarang ini. Kegiatan pengabdian masyarakat ini melibatkan guru dan siswa berjumlah 34 siswa yang ada di SMP Muhammadiyah 10 Matesih yang diawali dengan pengamatan terlibat aktif, wawancara mendalam secara langsung dilanjutkan dengan teknik Partisipatory Rural Appraisal kepada guru dan siswa di SMP Muhammadiyah 10 Matesih. Hasil kegiatan pengabdian masyarakat ini menunjukkan bahwa dengan adanya pendidikan etika dan karakter peduli lingkungan siswa yang ada di SMP Muhammadiyah 10 Matesih lebih menanggapi akan pentingnya lingkungan yang bersih, serta siswa di SMP Muhammadiyah 10 Matesih telah dapat memanfaatkan botol-botol bekas sebagai pot bunga dan lebih bertanggung jawab atas sampah yang ada di lingkungan sekolah dengan membuang sampah pada tempat sampah yang telah di sediakan oleh tim KKN-Dik maka dengan diadakannya pengabdian masyarakt pendidikan ini dapat mengetahui bahwa dengan diadakannya pendidikan etika dan karekter peduli lingkungan ini dapat menumbuhkan etika dan karakter siswa dalam bertanggung jawab terhadap lingkungan yang bersih, rapi, indah, dan nyaman. Oleh sebab itu, guru dan siswa perlu didorong secara berkala dan berkelanjutan dalam pendidikan etika dan karakter yang berbasis pada potensi lingkungan sosial-budaya sekolah.
\end{abstract}

\section{Pendahuluan}

Pengenalan dan kepedulian warga sekolah mengenai kebersihan sangatlah penting, kebersihan lingkungan menjadi tanggung jawab bersama dalam menciptakan kondisi yang nyaman dan sehat bagi seluruh warga sekolah serta lingkungan sekitar sekolah. Pengetahuan lingkungan hidup, etika lingkungan dengan sikap dan perilaku menjaga kelestarian lingkungan sangat berkaitan erat (Azhar, Basyir, \& Alfitri, 2016). Pembekalan pengetahuan lingkungan dibutuhkan untuk menunjang kesadaran siswa dalam menjaga kelestarian lingkungan. Menanamkan pemahaman dan kesadaran untuk peduli lingkungan melalui pendidikan di lingkungan sekolah akan lebih efektif karena akan menyentuh dan melekat pada peserta didik (Mulyana, 2009). 
Kerusakan lingkungan tidak dapat dihindari, namun dapat diperlambat dengan usaha-usaha kecil yang dilakukan warga sekolah (Sitti Hasnidar, 2019). Usaha dalam memperlambat kerusakan lingkungan yaitu dengan cara menumbuhkan kesadaran pentingnya menjaga kelestarian lingkungan, mengubah kebiasaan yang kurang baik terhadap kepedulian lingkungan, dan peduli pada kelestarian lingkungan.

Etika peduli lingkungan menjadi fokus pada penulisan artikel ini. Etika merupakan ilmu mengenai tabiat pengertian nilai baik buruk serta benar salah dalam mempergunakan ataupun bertindak pada sesuatu (Maidiantius, 2014). Sikap yang baik yang didasari pengetahuan yang kuat memberikan pengaruh yang besar terhadap hasil. Pemberian etika tentang kepedulian lingkuan akan memberikan rasa bersalah pada saat melanggarnya, jika seseorang memiliki etika yang baik terhadap lingkungan.

Kebersihan lingkungan dapat dirasakan oleh seluruh masyarakat sekolah untuk menunjang kenyamanan kegiatan belajar mengajar menjadi nyaman. Pembentukan karakter berkaitan erat dengan etika, dimana karakter yang kuat mampu mendorong siswa untuk berperilaku lebih baik. Pendidikan karakter dimaknai sebagai pendidikan nilai, pendidikan budi pekerti, pendidikan moral, pendidikan watak, yang bertujuan mengem-bangkan kemampuan siswa untuk memberikan keputusan baik, buruk, memelihara kebaikan, mewujudkan dan menebar kebaikan dalam kehidupan sehari - hari dengan sepenuh hati (Setiawati, 2017). Penanaman etika itu penting sejalan dengan penanaman pendidikan karakter yang akan menjadi dasar dalam penanaman dan pengembangan karakter bangsa (Sudrajat, 2011).

Peduli lingkungan dapat diajarkan melalui pendidikan formal (Fitriani, 2017), dalam pelajaran IPA siswa belajar mengenai beberapa masalah dalam lingkungan mengenai dampak dari sebuah tindakan serta belajar mengenai solusi yang dapat dilakukan. Pengaplikasian pelajaran kelas melalui praktik langsung yang diajarkan guru menjadi salah satu pilihan dimana siswa akan mengetahui keadaan secara langsung bukan hanya mengetahui teori yang diberikan.

Tindakan kecil membiasakan diri untuk peduli lingkungan yang dilakukan secara terus menerus akan menjadi kebiasaan baik bagi warga sekolah dan terkhusus untuk siswa. Pada saat ini, kebersihan menjadi masalah yang sulit dihindari di lingkungan sekolah karena tingkat kesadaran yang rendah. Kepedulian siswa akan kebersihan semakin menurun dengan terlihatnya beberapa hal diantaranya (1) masih banyak ditemukan sampah di lingkungan sekolah khususnya di dalam kelas, (2) banyak siswa yang masih membuang sampah sembarangan, (3) kamar mandi dan toilet siswa yang kotor dan berbau, (4) kerapian berpakaian yang masih belum terlihat.

Kebersihan menjadi sebuah cerminan kepribadian seseorang, wujud karakter baik tampak dalam bentuk integritas moral, berupa paduan antara pemahaman moral, dengan motivasi (Isnarmi, 2016). Masalah kebersihan tidak hanya dilakukan melalui tindakan semata, namun harus didukung dengan adanya rasa yang tumbuh pada perasaan seseorang untuk menumbuhkan nilai karakter yang baik.

Ketidakpeduliaan akan kebersihan lingkungan sekolah khususnya kelas dapat memperlambat efektifitas belajar dan membuat lingkungan tidak nyaman atau tidak indah dipandang. Begitu pula sebaliknya, kepedulian terhadap kebersihan dapat memberikan manfaat, seperti keefektifitasan belajar menjadi lancar dan suasana belajar akan nyaman.

Kebersihan juga penting bagi kesehatan, karena dalam tubuh yang sehat terdapat jiwa yang kuat. Demikian juga dengan lingkungan yang ada di kelas kita, kelas yang kita tempati belajar. Lingkungan sekolah yang bersih merupakan salah satu unsur yang harus ada, dibina dan dikembangkan terus agar dalam proses pendidikan yang berjalan mencapai hasil yang diharapkan. Pembinaan tersebut sangat terbantu dengan hadirnya para mahasiswa yang melaksanakan kegiatan KKN-Dik. Pelaksanaan KKN merupakan manifestasi dari Tri Darma Perguruan Tinggi yang ketiga, yaitu pengabdian kepada masyarakat. Kegiatan KKN dimaksudkan untuk membantu masyarakat dalam memecahkan permasalahan-permasalahan yang dihadapi.KKN juga sebagai salah satu wahana bagi mahasiswa untuk mengaplikasikan teori-teori yang dimilikinya kedalam sebuah wujud nyata pengabdian kepada masyarakat. Melalui KKN, diharapkan mahasiswa dapat mengaktualisasikan disiplin ilmu yang masih dalam tataran teoretis terhadap realisasi praktis dengan bentuk pengabdian dan pendampingan langsung kepada masyarakat disamping tim pelaksanaan yang dilakukan sebagai usaha pengembangan ilmu yang didapat sebelumnya. 
Kegiatan KKN-Dik pada era disrupsi pendidikan ini memiliki peranan yang penting, karena hakikatnya KKN-Dik FKIP UMS ini memiliki tujuan untuk mengedepankan Sekolah (Muhammadiyah) untuk lebih maju, mengunggulkan Sekolah (Muhammadyah) menjadi lebih unggul, memberdayakan Sekolah (Muhammadiyah) berdaya saing, menci-rikhususkan Sekolah (Muhammadiyah) supaya berciri kuat, dan menjadikan sekolah (Muhammadiyah menjadi ramai, gembira, serta menjadikan suatu satuan pendidikan yang dipercaya masyarakat, bermuara pada peserta didik yang cukup melimpah.

\section{Metode Pelaksanaan}

Kegiatan pengamdian masyarakat ini dilaksanakan di lapangan yaitu terjun langsung kelapangan. Menurut Burgess (2002) kegiatan lapangan memfokuskan mengatasi permasalahan yang ada sejak memulai pengamatan, mendapatkan akses, memilih informan, memenuhi etika pelaksanaan pengabdian sampai mengumpulkan data, melaksanakan kegiatan, menganalisis dan tahap pelaporan. Kegiatan pengabdian masyarakat pendidikan lapangan ini juga tidak memiliki model yang linier karena tim pelaksana berhadapan dengan berbagai situasi social yang sangat kompleks sehingga fleksibilitas mendapat penekanan. Kegiatan pengabdian masyarakat ini berlangsung pada tanggal 21 Januari 2020 sampai 03 Maret 2020 atau selama 1,5 bulan. Kegiatan pengabdian masyarakat ini dilakukan di SMP Muhammadiyah 10 Matesih. Metode yang dilakukan untuk memperoleh data ini adalah dengan menggunakan pengamatan, observasi dan wawancara secara langsung terhadap siswa, keadaan sekolah serta keseluruhan yang ada di sekolah tersebut selama KKN-Dik di SMP Muhammadiyah 10 Matesih dengan metode utama Partisipatory Rural Apparisal.

\section{Hasil Pelaksanaan dan Pembahasan}

Persepsi merupakan kemampuan seseorang dalam menginterpretasikan serta memberikan stimulus terhadap lingkungan melalui alat indera sehingga seseorang memperoleh makna. persepsi seseorang akan mempengaruhi terhadap tindakan perilaku, baik persepsi positif dan persepsi negatif. Contoh yang terjadi di sekolah yakni kebersihan lingkungan sekolah. apabila persepsi siswa itu benar, maka siswa mampu bersikap benar terhadap kebersihan lingkungan sekolah. siswa mempunyai kepedulian, kenyamanan, dan keasrian terhadap kebersihnan lingkungan sekolah.

Kegiatan pengabdian mamsyarakt ini dilakukan di

SMP Muhammadiyah 10 Matesih. Tim pelaksana melakukan pengamatan kepada seluruh siswa SMP Muhammadiyah 10 Matesih yang terdiri dari kelas VII terdiri dari 9 siswa, kelas VIII terdiri dari 16 siswa, dan kelas IX terdiri dari 9 siswa. Jadi total seluruh siswa SMP Muhammadiyah 10 Matesih sejumlah 34 siswa. Setelah melakukan pengamatan terha-dap siswa tim pelaksana memiliki tiga aspek diantaranya:

\section{Gambaran Umum Penguatan Pendidikan Etika dan Karakter}

Letak bangunan sekolah ini terdiri dari masjid, ruang kepala sekolah, ruang guru, ruang perpustakaan, ruang uks, ruang kelas VII, VIII, dan IX serta WC. Hasil pengamatan kami bahwa kondisi ruangan di SMP Muhammadiyah 10 Matesih ini kurang bersih dan kurang tertata rapi. Minimnya alat kebersihan dan tempat pembuangan sampah yang membuat lingkungan kurang bersih. Sehingga tim pelaksana membuat program kerja membuat tempat sampah dari ember, jumat bersih dan bersih perpustakaan. Tim pelaksana mulai melakukan program kerja dengan pembuatan tempat sampah, kurang lebih satu minggu tim pelaksana mengerjakan pembuatan tempat sampah. Hal ini agar sampah yang dulunya berserakan manjadi lebih rapi setelah terdapat tempat sampah. Kemudian kondisi perpustakan di SMP Muhammadiyah 10 sangat berantakan serta terdapat banyak debu dan juga mejanya yang tidak tertata rapi, sehingga tim pelaksana mengajak para siswa untuk bergotong royong membersihkan perpustakaan tersebut, supaya siswa yang berkunjung keperpustakan dapat merasa lebih nyaman.

Gambaran umum implementasi penguatan pendidikan etika dan karakter diilustrasikan melalui gambar 1. Pendidikan etika dan karakter bukan untuk diteoresikan tetapi dipraktikkan dan dibiasakan dengan tetap mempertimbangkan lingkungan sosial-budaya masyarakat di sekiatrnya (Prayitno, 2011; Fatma et al., 2019). 

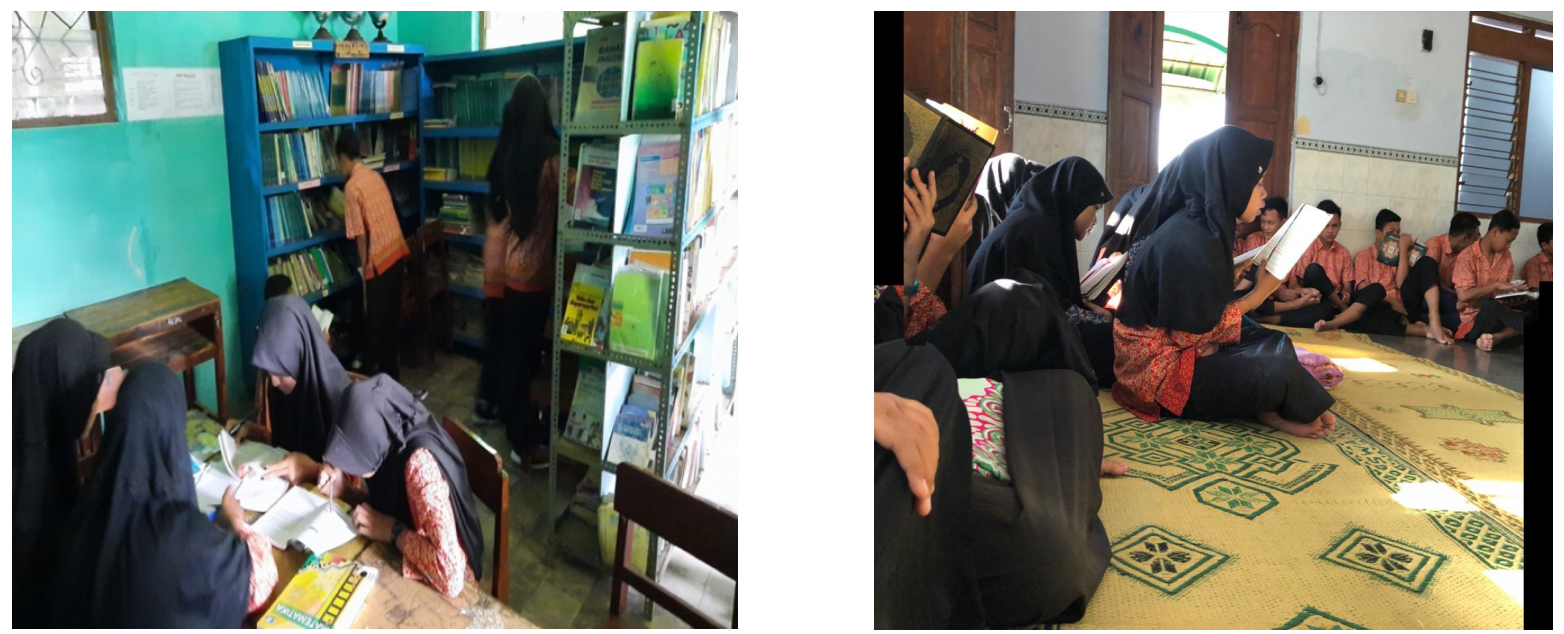

Gambar 1. Penguatan Pendidikan Etika \& Karakter di SMP Mumammadiyah 10 Matesih

\section{Implementasi Penguatan Pendidikan Etika dan Karakter Siswa}

Etika merupakan perilaku manusia dilihat dari baik buruknya dengan ajaran yang berhubungan dengan perintah dan larangan. Etika memberikan arahan bagaimana manusia harus hidup secara baik. Dalam pendidikan merupakan hal yang sangat penting upaya dalam membentuk, mengarahkan serta mewujudkan manusia berakhlak mulia dan beretika. Sehingga tim pelaksana melakukan pengamatan kepada para siswa apakah siswa mampu beretika kepada guru. Ternyata banyak siswa yang tidak mematuhi tata tertib dan tidak sopan terhadap guru. Dari hasil pengamatan tim pelaksana, siswa datang terlambat padahal bel masuk jam 07.00 tetapi siswa baru sampai sekolah pukul 07.10 atau lebih. Sebenarnya guru sudah memberikan teguran ataupun hukuman ketika siswa datang terlambat tetapi siswa mengabaikan teguran tersebut. kemudian cara berpakain, siswa masih melanggar tata tertib. Siswa datang ke sekolah dengan baju dikeluarkan, tidak menggunakan dasi, ikat pinggang, sepatu yang tidak hitam. Sikap siswa sangat memprihatinkan, guru di SMP
Muhammadiyah 10 Matesih harus sabar menghadapi anak didiknya. Sehingga siswa perlu menanamkan nilai etika di sekolah dengan cara pemberian motivasi dari guru yang nanti siswa akan lebih tahu mana yang baik dilakukan.

Kemudian karakter merupakan perilaku manusia yang berhubungan dengan sikap, perkataan, perbuatan berdasarkan norma-norma agama, hukum. Penerapan pendidikan karakter tersebut dapat memberikan pembentukan kepribadian seseorang Menurut Nuh (2010) pembentukan karakter perlu dilakukan sejak usia dini, ketika karakter sudah terbentuk sejak dini maka tidak mudah untuk mengubah karakter seseorang. Untuk mencapai karakter siswa maka tim pelaksana dan guru mengajarkan tentang kejujuran, keberanian, tanggung jawab.

Seperti diilustrasikan melalui dokumen kegiatan pada gambar 2 menunjukkan bahwa pendidikan etika dan karakter memerlukan kedisiplinan dan kesungguhan dalam penerapannya. Etika dan karakter menjadi faktor penting dalam membentuk sosok dan jati diri anak di era global ini. Karakter anak bahkan bisa meningkatkan kemampuan sains anak (Aini, et all., 2019). 

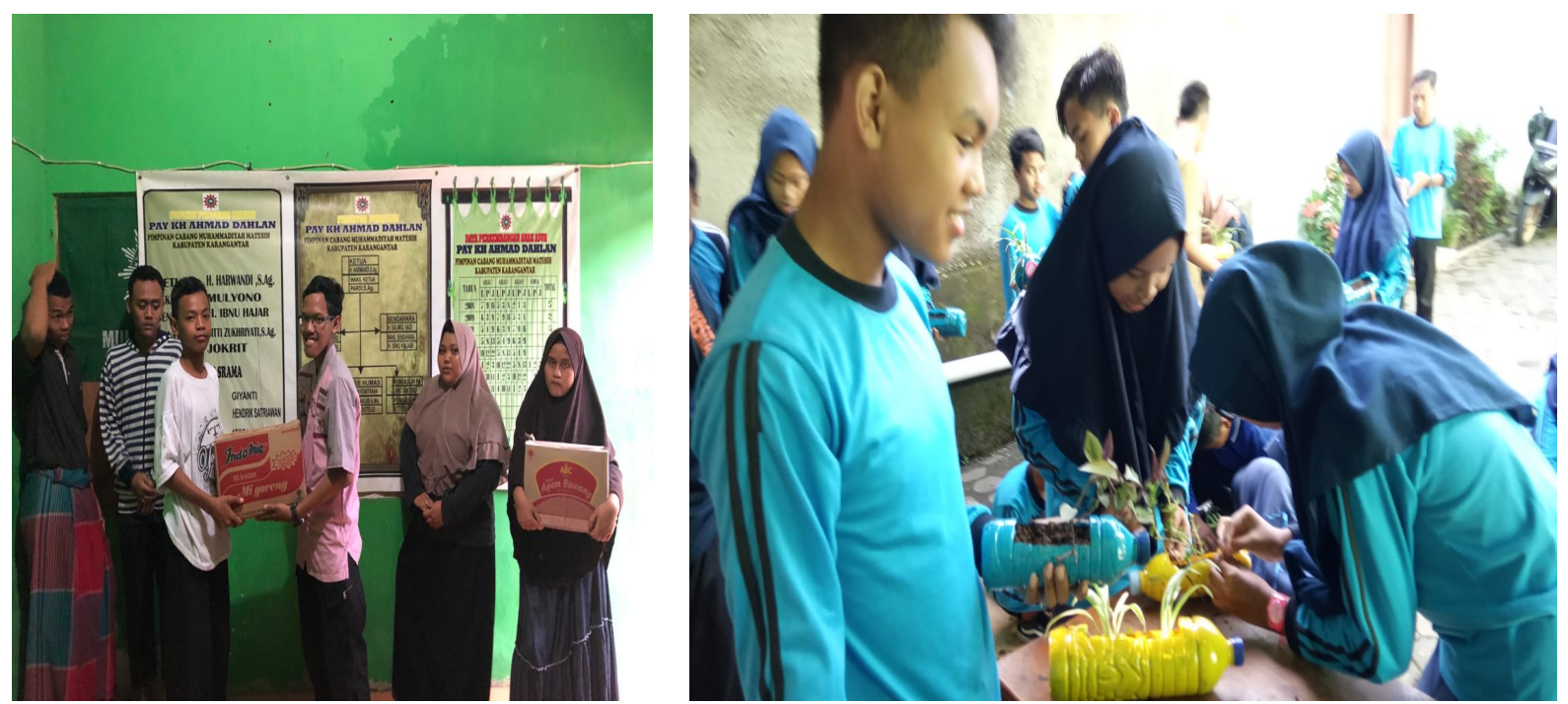

Gambar 2. Implementasi Penguatan Pendidikan Etika \& Karakter

\section{Revitalisasi Lingkungan Sosial-Budaya Beretika dan Berkarakter}

Lingkungan merupakan sesuatu yang kita lihat dan kita dapati setiap hari. Lingkungan juga sangat dekat dengan kehidupan manusia. Maka dari itu, lingkungan merupakan sesuatu yang harus kita jaga kelestariannya. Sekarang ini, sedikit orang yang peduli terhadap lingkungan. Oleh karena itu, untuk peningkatan kepedulian peserta didik terhadap lingkungnan dilakukan melalui pembiasaan terbimbing dan terkontrol dengan penanaman tanaman pilihan kelompok dengan kewajiban merawat dan memelihara selama disekolah secara kelompok hingga tanaman tumbuh dengan benar dan baik memberikan kewajiban menyiram, menyemai dan merawat, dengan bimbingan dan kontrol oleh guru pembimbing. Karena selama ini kewajiban yang dilakukan oleh sekolah sebagian besar hanya menanam, tetapi tidak ada kewajiban untuk memelihara. Untuk itu maka sangat diperlukan pendidikan lingkungan hidup di lembagalembaga pendidikan dengan pembiasaan terbimbing dan terkontrol seperti di SMP Muhammadiyah 10 Matesih.

Lingkungan sosial budaya sekolah perlu dimanfaatkan secara maksimal dalalam rangka pembentukan etika dan kepribadian anak. Lingkungan sosial-budaya sekolah ini merupakan salah satu faktor penting dalam pembentukan karakter anak. Lingkungan sosial budaya ini perlu dimanfaatkan untuk meningkatkan prestasi belajar melalui berbagai layanan bimbingan siswa (Prasetya, et al., 2019).

Seperti yang kita lihat, di SMP Muhammadiyah 10 Matesih sebelumnya tidak menyiapkan tempat sampah untuk siswanya yang ingin membuang sampah. Siswa cenderung membuang sampah sembarangan. Dan di SMP Muhammadiyah 10 Matesih juga terasa gersang karena belum terlihat banyaknya tanaman yang bisa membuat sejuk lingkungan.

Setelah diberikan pengarahan terhadap pentingnya kita menjaga dan merawat lingkungan sekitar, dan juga disediakan tempat sampah di setiap sudut-sudut sekolah membuat siswa mulai sadar untuk membuang sampah pada tempatnya yang sudah disediakan. Siswa juga bersemangat dan kompak untuk menghijaukan lingkungan dengan cara memanfaatkan botol-botol bekas minuman untuk dijadikan pot sebagai media tanam. Disamping itu, siswa juga sering mengingatkan temannya untuk membuang sampah di tempat yang sudah disediakan.

Peduli lingkungan dapat dilakukan melalui Pembiasaan terbimbing dan terkontrol dengan memberi aktifitas kepada peserta didik melalui kegiatan penanaman tanaman secara kelompok dilingkungan sekolah diikuti tanggungjawab pemeliharaan dan perawatannya selama anak didik di sekolah terbimbing dan terkontrol hingga tanaman tumbuh (Fuadi, 2018). 


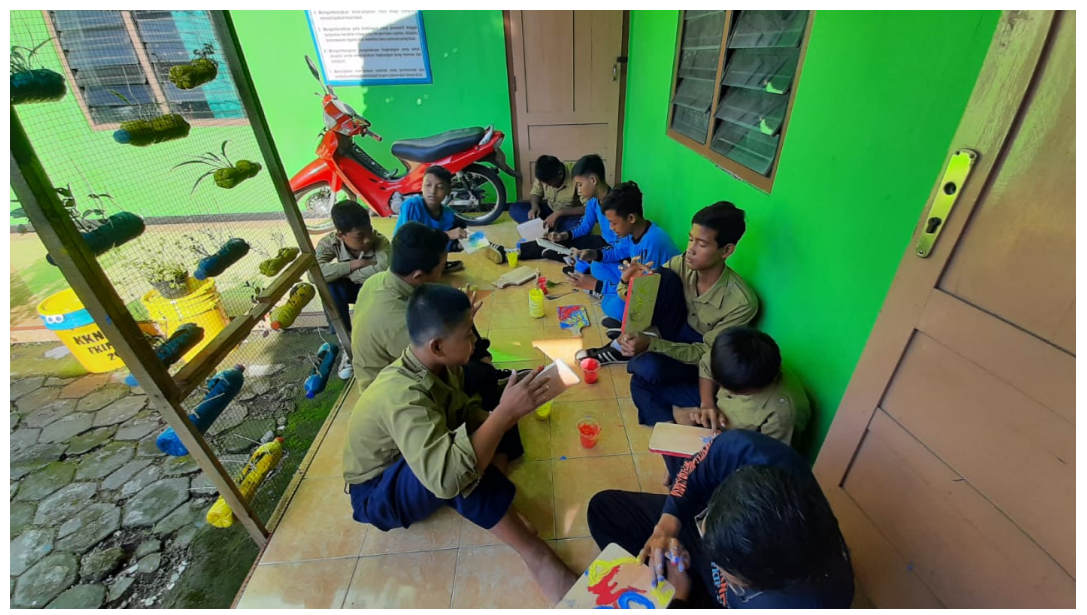

Gambar 3. Pemanfaatan Lingkungan Sosial-Budaya dalam Beretika dan Berkarakter

\section{Simpulan}

Bentuk pendidikan etika dan karakter yang sudah kami terapkan pada siswa siswi SMP Muhammadiyah 10 Matesih, Karang-anyar ini cukup memberikan dampak yang positif bagi siswa siswi secara khususnya dan guruguru nya secara umum. Siswa menjadi lebih tau, paham dan sadar pentingnya karakter yang baik dan menjaga lingkungan agar tempat yang ia singgahi nyaman untuk beraktifitas. Selain hanya dengan arahan secara lisan untuk mendidik karakter, kami juga membuat dengan metode dan cara lain agar siswa mempunyai pengalaman pendidikan yang beda dan menyenangkan. Hal tersebut diharapkan dapat membuat siswa siswi menjadi anak harapan bangsa yang mempunyai karakter baik dan bisa membuat suasana belajar lebih menyenangkan serta fokus agar mencapai prestasi terbaik.

\section{Daftar Pustaka}

Aini, S. I. Y. I. N., Firdiansyah, B. A., Desta, D., Tamarani, F. D., \& Sistiasih, V. S. (2019). Penggunaan Pendekatan SAVI (Somatik Auditori Visual Intelektual) untuk Meningkatkan Keterampilan Proses Sains Siswa SDN Donoyudan. Buletin KKN Pendidikan, $1(1)$.

Burgess, RG. (2002).Inthe field: An introduction to field research. Taylor \& Francis. www.ebookstore.tandf.co.uk.

Fatma, F., Prayitno, H. J., Jamaludin, N., Jha, G. K., \& Badri, T. I. (2019). Directive Speech Acts in Academic Discourse: Ethnography of Communication from Gender Perspective in Higher Education. Indonesian Journal on Learning and Advanced Education (IJOLAE), 2(1), 27-46.

Fitriani, R. (2017). Perilaku Peduli Lingkungan Pada
Siswa Kelas X Sma Muhammadiyah 1 Yogykarta. Jurnal Pendidikan Teknik Boga Tahun 2017, 1-11.

Fuadi, D., Suwandi, J., \& Jumali, J. (2018, November). Growing Life Skill through Accounting Learning in Millennial Era. In Profunedu International Conference Proceeding (Vol. 1, pp. 361-370).

Isnarmi, M. (2016). Pendekatan Kritis-Transformatif dalam PKn: Sebuah Upaya Pengembangan Karakter (Good Character). Jurnal Social Science.

Maidiantius, T. (2014). Etika Dalam Pendidikan. Jaffray.

Mardiana, Dinny. "Internalisasi Nilai Etika Lingkungan Di Sekolah Dasar." Sosio Religi: Jurnal Kajian Pendidikan Umum 15.1 (2017).

Mulyana, Rachmat. "Penanaman etika lingkungan melalui sekolah perduli dan berbudaya lingkungan." Jurnal Tabularasa 6.2 (2009): 175-180.

Prasetya, I., Ulima, E. T., Jayanti, I. D., Pangestu, S. G., Anggraeni, R., \& Arfiah, S. (2019). Kegiatan Bimbingan Belajar dalam Meningkatkan Minat Belajar Siswa di Kelurahan Bolong Karanganyar. Buletin KKN Pendidikan, 1(1).

Prayitno, H. J. (2011). Teknik dan Strategi Tindak Kesantunan Direktif di Kalangan Andik SD Berlatar Belakang Budaya Jawa. Kajian Linguistik dan Sastra, 23(2), 204-218.

Setiawati, N. A. (2017). Pendidikan Karakter Sebagai Pilar Pembentukan Karakter Bangsa. Seminar Nasional Tahunan Fakultas Ilmu Sosial Universitas Negeri Medan, 1(1), 348-352.

Sitti Hasnidar, S. H. (2019). Pendidikan Estetika dan Karakter Peduli Lingkungan Sekolah. Jurnal Serambi Ilmu, 20(1), 97. https://doi.org/10.32672/si.v20il.997

Sudarsana, I. Ketut. "Membentuk Karakter Siswa Sekolah Dasar melalui Pendidikan Alam Terbuka." Prosiding Nasional (2016). 